\title{
National Parks and social involvement - an argument ${ }^{1}$
}

\section{J.A. LOADER}

Loader, J.A. 1994. National Parks and social involvement - an argument. Koedoe 37(1): 137-148. Pretoria. ISSN 0075-6458.

Discrimination, whether institutionalised or not, is described as the expression of prejudice. which. it is argued, is derived from projectionism, or the supposition that one's own perception coincides with reality and is therefore the only valid one. It is the result of naive ignorance of the world view(s) by which human attitudes are shaped. By means of the ecologically congenial concepts of interrelatedness and holism, it is here argued as an alternative that social involvement is (or, should be) an intrinsic part of conservation. A possible model for the purpose and some practical considerations are suggested.

Key words: social involvement, prejudice, discrimination, interrelationship.

J.A. Loader, Faculty of Theology, University of South Africa, P.O. Box 392, Pretoria, 000I Republic of South Africa.

\section{Introduction}

This paper focuses on the social involvement of National Parks. It is designed as an argument, notably that social involvement is logically an intrinsic part of conservation. I would like to commence my argument by stating that we have no choice but to take this topic very seriously. It simply has to be done. 'Having to do it' may have a fourfold meaning:

- It is an issue regarded as topical in the highest echelons of the National Parks Board. In other words, those working within the National Parks Board environment have to do so because they are told to do so.

- Since political and socio-economic realities are forcing us to draw the issues of the day into the ambit of our reflections, we have no alternative but to respond.
- We have to pay attention to the social issues because we are involved in them whether we choose to or not.

- There are scientific reasons for acknowledging that the social aspect of the environment is inherently part of the mission of an environmental organisation.

I shall argue that all four reasons are true. In the light of the recent spate of public controversies involving National Parks and the publicity given to the topic (Robinson 1993) one can safely say that the first two reasons speak for themselves (although I shall conclude with the statement that we should not be socially involved because we have to but because it is right). The last two reasons for undertaking the enterprise will be woven into the argument that is subsequently developed. I shall offer two sections, suggesting, first, a framework within which to operate, second, the basic concepts involved and how they relate to the concept of conservation.

1 An edited version of material used for a workshop presented to the wardens of the southern national parks, held at Geelbek, West Coast National Park on 24 November 1993. 


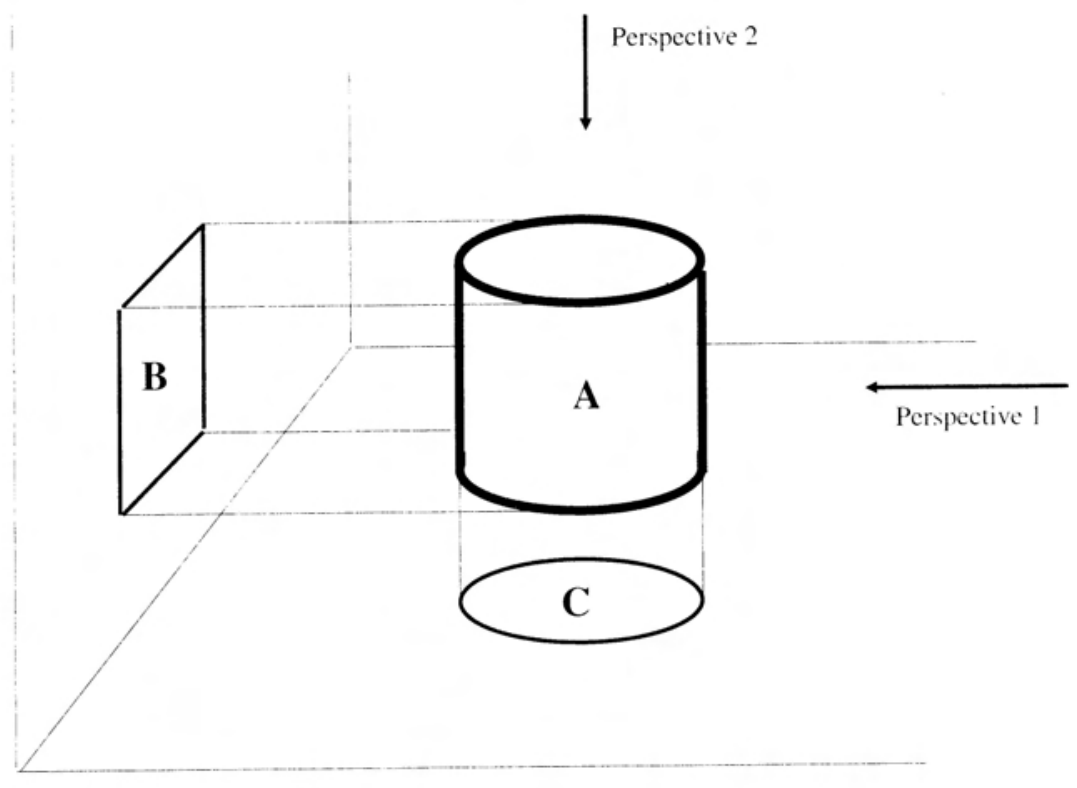

Fig. 1.

\section{A framework for reflection}

\section{The purpose}

The letter of commission for this undertaking states that the overarching purpose is to contribute towards the creation of 'meaningful relationships' between national parks and their neighbouring communities while, in the process, attention is to be paid to the phenomena of prejudice and discrimination in order to enhance meaningful dialogue and the handling of conflict. This cannot be achieved without a clear framework within which to operate. We should not only know what we are talking about (which, of course, is necessary in itself), but we should especially consider what makes us talk, that is, the suppositions and ideas that make us believe the things we believe and act the way we act.

\section{World view and philosophy}

A popular notion has it that philosophy is a useless academic activity with which one "can do nothing". That is the origin of the expression that something is "only of academic importance', meaning that it is actually of no consequence. On the other hand reference is often made to, say. the 'philosophy' of conservation or even the 'philosophy' behind fuel injection in motor cars. In the former case the basic theory of the essence and meaning of conservation is meant. and the latter refers to the reason why cars are manufactured with fuel injection. These examples illustrate that the term 'philosophy' is employed in a loose and unclear way. This slackness of parlance is an impediment to sharp and disciplined reflection on a topic as the one occupying us in this paper, and calls for clarification.

Every human has a world view which can be defined as a basic way of looking at reality. We presuppose certain things which we regard as self-evident and for which we neither have nor require proof. For instance, that our environment is not illusory but really exists physically, that we can know, analyse and 
explatin it, that life is worth living, that it has meaning, and so on. A philosophy takes stock of this; it is the verbalising of such a basic set of convictions, accounting for how we think and believe.

Accordingly, not having a philosophy means being unaware of the fact that one's views are formed by one's world view. It means being naive - whether one has never heard the word or whether one imagines that philosophy is only unpractical academic exercises. Such a person is both dangerous and exposed to danger. If one is ignorant of the determining power of one's world view, then one is without control over one's views and simultaneously defenceless against them.

Our world view determines how we observe things. It contains the presuppositions from which our thinking proceeds and according to which we form perceptions and judgements. The perspective from which we look at an object causes that object to appear different from what it looks like when observed from another perspective. If we, for instance, look at a cylindrical object such as a flashlight battery (A) from the side, we see a rectangle (B). When we look at the same battery from the top, we see a circle (C), and to us as observers of the projection $\mathrm{B}$ and $\mathrm{C}$ appear different still. The battery is neither a circle nor a rectangle, but different observers see it as a circle or a rectangle because their vantage points differ (see Fig. 1).

Their observations or perceptions of the same reality differ because the circumstances under which they look at reality are not the same. This holds good for all observation what the essence of the world is, what the meaning of life is, what is good and bad, what is valuable, and so on. A person's world view provides the interpretative framework within which all information is assimilated and all convictions are formed.

Philosophy entails becoming aware of this and mapping it out. In the same way that a map is a systematic representation of the world, a philosophy is a systematic representation of one's world view. It is the theory according to which one chooses priorities, determines goals and decides on appropriate methods.

This may be illustrated by some (simplified) examples from the classic philosophical systems.

- When one starts from the presupposition that reality consists essentially of matter, one would develop a materialist philosophy. This philosophy would then determine the materialist's values, what should be striven for and how it should be striven for. One (though by no means the only) well-known example of such a programme is the so-called dialectical materialism as set out by Karl Marx (1859, 1867) and Friedrich Engels (1845-1846) (cf. McLellan 1978:124, who points out that Marx did not go so far as to claim that only matter exists).

- When one proceeds from the presupposition that the essence of reality is spirit or ideas (which is today even claimed by some physicists), one would develop an idealistic philosophy. A prime example of this would be the philosophy of Georg Wilhelm Friedrich Hegel (1807), who exerted enormous influence in the development of evolusionistic theories.

- The presupposition that reality cannot really be known or that all that exists is only illusion, leads to the development of a sceptical philosophy. such as that of David Hume (1740).

- The view that reality is a connected whole leads to a holistic philosophy which endeavours to substantiate that all elements of reality are related. The most prominent example of such a philosophy is the thought of J. C. Smuts (1926) and its variants that are rapidly becoming more influential in contemporary ecological circles. 
We can continue in the same strain to show that there are many philosophies or philosophical systems by means of which people endeavour to conceptualise and verbalise the essence of the world and therefore the correct way in which humans should act (ethics). Philosophies are not like political parties between which one has to choose in order to be able to vote for one of them. Combinations can develop and elements from one system can be combined and integrated with elements from another in a new system. In this way. for example, the idealist philosophy of Hegel, based as it is on the view that the essence of the world is spirit, made substantial contributions via its conception of development to the theories of evolution which became so important in sciences such as biology and ecology.

Often a popular world view and the accompanying philosophy or quasi-philosophy are extremely naive. A simple and widespread world view (especially in the Western World) is that the world not only exists, but that it exists for the sake of humans. This can lead to the simple philosophy that life makes sense if its demands can be manipulated to one's own advantage. This view determines the attitudes and choices of millions of people, South Africa not excluded.

\section{Projectionism and perspectivism}

The next step in our argument is to show how these considerations pertain to the concern of this paper. When people are not aware of these forces, they are exposed to the danger of projectionism. That means that they suppose naively that the vantage point from which they look at reality is the only or the only valid or the only worthwhile one. Expressed in terms of our battery-image (cf. Fig. 1 ), such a person projects his/her own way of perceiving onto reality. In this case one would claim that the battery is a circle, deny that it is a rectangle (on the grounds of the quasi-substantiation that one can 'see with one's own eyes' that it is round) and. moreover. one would identify one's perception of reality with reality itself. It is not even considered that other dimensions also exist and the phenomenon of, say, a cone plays no role whatsoever in the mind of such an observer. This obviates the problem of communication: How would this observer communicate with another observer who looks at the battery from the side and who is just as naively convinced that the object is a rectangle on the identical grounds of being able to see it with his/her own eyes? This brings us to the phenomenon of prejudice to which we shall be paying more attention shortly.

The opposite of projectionism is perspectivism. It occurs when people realise that one and the same object can be looked at from different angles, that is, from different perspectives. In this way room is left for the acknowledgement that another observer can look at the same object from another angle and therefore experience it differently and describe it differently without having to be 'wrong' if the first observer is 'right'. Perspectivism does not succumb to the error of identifying one's own perception with reality itself. For this reason the world of a person with a perspectivist approach does not fall apart at the discovery that another perspective can also be true or that it can also contain valuable elements. Finally, such a person does not start doubting his/her own position when confronted by others and therefore is not afraid of others or in need of appearing 'strong'.

\section{'Objectivity'}

Just as nobody can look at an object without doing so from a specific vantage point. so it is impossible to be fully objective. Every observation is made from a specific angle and is therefore coloured by all sorts of influences. From the east. for instance, Ship Mountain does not resemble a ship at all. but looks much more like a pyramid. From the north it can be likened to a ship, but only by people who have already seen a ship. Others. who have never seen a ship, cannot see the resemblance, and still others, who have seen 
a capsized ship floating at sea. think that the name can only be explained as a reference to a shipwreck. There is no one correct. objective view.

Therefore one cannot claim that one's own view must be right because it is 'objective'. This holds good for all sciences, both natural sciences and the humanities including the social sciences. Neither opinions in the political, economic and social lields nor those in the so-called 'exact' fields can claim full objectivity. It is not possible to lully practise the journalistic claim to 'tell it like it is' (which, incidentally, itself is highly biased propaganda). What we can do, is to strive for impartiality.

Feasible objectivity entails:

- the consciousness that our world view and convictions colour our observations

- avoidance of such suppositions running amuck with us

- exposure to the broadening effect of at many other perspectives as possible

- the critical questioning of all options including our own.

Objeclivity in this sense does not mean that one endeavours to be tolally value-free or 'uncommitted', but simply that one is fair by genuinely exposing and testing one's own view before making a decision or reaching a conclusion. It is a form of perspectivism, in other words, the retention of perspective.

\section{Prejudice}

The opposite of objectivity in this sense is prejudice (cf. Baron \& Byrne 1987). In fact. prejudice is meraly a form of projectionism. It is an attitude held by a person who is unwilling to expose that attitude to testing (cf. Roucek \& Warren 1966). One of the main characteristics of prejudice is that it contains an intrinsic self-contradiction. On the surface prejudice usually appears to be a strong conviction. However, the fear of being exposed to other opinions or of being critically examined, betrays a deep mistrust in the strength of that conviction. After all, if a conviction is as strong as claimed or implied, there need be no fear of allowing it to compete with others on an equal playing ground.

Prejudice can be affirmative or negatory.

- Affirmative prejudice is to state what one believes and to stick to it regardless of the opinions and insights that may be forthcoming from other perspectives. Good synonyms for this kind of prejudice may be 'doggedness' and 'intransigence'.

- Negatory prejudice is a negative attitude to another perspective and/or the people associated with the other perspective. We often encounter negatory prejudice in the world of science and scholarship. This happens, for example, when a scientist trained in the positivist tradition (that absolutely true facts can be established on condition that only that which can be measured is regarded valid, of which the classic formulation was given by Comte 1830-42) is not prepared to consider other views of validity (say, the proposition often encountered under the influence of contemporary physics, that the nature of what we see is alfected by the very act of our observing). However, the most topical kind of prejudice is of a social nature and takes the form of a negative attitude towards a specitic social group. Sometimes it is seemingly petty, for instance, 'women can't drive' or 'men can't cook'. Sometimes it becomes more serious, as in the hatred of homosexuals entertained by many male heterosexuals. And often it takes on the extremely serious complexion of ethnic prejudice.

Since the latter is our major concern in this paper. we shall be concentrating somewhat more on this form of prejudice. Ethnic prejudice has been in the world for centuries. The history of the suffering of the Jews and the European Gypsies illustrate this point clearly. A negative attitude was directed at any indi- 
vidual belonging to one of these groups merely on the grounds of his or her belonging to that group.

Such prejudice is rife with two complementary logical fallacies, notably generalisation and individualisation. To generalise means to transfer the real or imagined characteristics of an individual to the social group to which he or she belongs without checking the correctness of the transference; individualisation works the other way round. Despite the fact that formal logic has for centuries shown this to be illegitimate reasoning ( $\mathrm{cf}$. Sinclair 1960 ) and that no worthwhile scientist will tolerate it in research, it is often found in social practice. It gives rise to stereotypes that soon begin to entrench themselves in a society (cf. Hogg \& Abrams 1988). Some examples:

- Refusal to employ a black driver because 'blacks can't see three-dimensionally' (individualisation).

- A black farm worker's experience of being whipped by his employer leading to the assumption that all farmers and, further still, all white people are cruel (generalisation).

- The killing of a white farmer because he belongs to the category of 'Boer settlers', or the violence against a commuter in retaliation for what the group to which he belongs is claimed to have done to others (individualisation).

- A white farmer's experience of an employee's having broken his equipment causing the assumption that blacks as such are unhandy (generalisation).

- Finding out that the party who bad the better of one in a deal is Jewish. may evoke the perception that Jews cannot be trusted in business (generalisation).

These stereotypes are often accompanied by linguistic labels, such as 'Boer' (= 'boor'). 'kaffir', 'hotnot', 'Jood' (= deceitful person), 'Rooinek', 'backvelder' and the like. Once this has happened, the label itself contributes to the strengthening of the force of the stereotype and the concomitant hardening of the prejudice. It thus becomes a force propelled by its own momentum.

\section{Discrimination}

Social prejudice is expressed in discrimination. which is actually applied prejudice. Discrimination appears in various degrees. It can be mild, for instance in the form of avoidance (where groups and the members of groups tend to eschew each other's company or even any contact at all). It can, however, be much stronger. such as the denial of access to public amenities, employment, residential areas, education and the like (Baron \& Byrne 1987). In its worst form discrimination is institutionalised. This means that applied prejudice is sanctioned by law. which makes it illegal not to discriminate against different categories of people.

Once this stage has been reached, it is extremely difficult to dismantle discrimination and even more difficult to overcome the prejudice whence it emanates. This is so because prejudice is an attitude, a state of mind which, like all attitudes, is rooted in a number of very powerful factors (Baron \& Byrne 1987);

- Experiential reduction. People have such a bewildering assortment of experiences that they tend to simplify them in order to feel able to handle them. Humans tend to dislike complexity and therefore tend to reduce information. This is often done by forming mental short-cuts, by categorising and labeling things into cut-and-dried attitudes to be invoked and used at convenience.

- Social learning. This starts with birth, when humans start learning attitudes by following the models of others and by being conditioned to conform to established attitudes. In its institutionalised form this is called 'indoctrination', where official institutions like the schooling system are used to systematically condition the attitudes of a group. The less indepen- 
dence of mind people have, that is, the less creative they are and the less they think for themselves, the less they will be able to withstand and/or overcome the effects of indoctrination.

- Vested interests. The attitudes of people are usually strongly shaped by their own interests. If one is part of the privileged sector of a society, one is prone to have hostile attitudes towards groups that one perceives as threats to those privileges. If one is part of the under- or non-privileged sector, one's attitudes tend to be hostile towards that part of society which is perceived to withhold access to prosperity.

\section{Conflict}

It should be obvious that these factors make for conflict between individuals and in societies. If we do not understand the factors underlying conflict, we shall not be able to address the practical issues of a conflict situation in any meaningful way. Therefore we shall have to take stock of what we have found so far. Far from being about 'philosophical' (read: 'abstract') or 'academic' (read: 'useless'), I think it will prove to have addressed a number of highly practical and vital matters.

\section{Summary}

- Nobody is without a world view which shapes his/her views and attitudes.

- Being unaware of these makes one defenceless, susceptible to manipulation and incapable of sound judgement.

- Such naivité leads to projectionism, the supposition that one's own perception coincides with reality and that it is therefore the only valid one.

- In social context this in turn leads to prejudice which is expressed in unfairness and either de facto or institutionalised discrimination and hardening conflict.

Therefore any alternative needs to accommodate the basics of
- explicitness of world views,

- perspectivist recognition of various views of reality

- and attainable 'objectivity' in the form of exposure to other views and critical interaction.

It is not without meaning that this set of desiderata is exactly what is required of a good scientist. It is also thought-provoking to realise that these processes are universals. We cannot choose or refuse to be part of them, to take part in them or to be affected by them. We can choose or refuse to be ignorant of them, to ignore them and therefore to relinquish control of them.

\section{The central issue of meaningful social re- lationships}

\section{Interrelationship}

In the commission for the delivering of this paper the management of Southern Parks implicitly states that meaningful relationships between communities are a matter of interrelationships. Since the commission states that National Parks and their neighbouring communities must establish meaningful relationships, it implies that both, parks and neighbours, need each other. That is to say that they are interrelated. This is the key concept in the establishment and maintaining of meaningful social relationships.

The concept of interrelationship as used in this context should appeal to those who devote their careers to the study of ecology and the conservation of ecosystems. It is significant that the father of sociology, Auguste Comte (1798-1857), considered this discipline as a 'natural science' and not as a 'science of the mind' (cf. Urmson 1983). This will prove to be not so surprising, for, as we now proceed to pay attention to the central concept in the study of social relationships, we shall find that the concept of interrelationship 
is just as central to the study of human social relationships as to the study of ecosystems.

The basic concept in social relationships is essentially an ecological concept. This word is derived from the Greek words oikos ('ekos') and logos, respectively 'house' and 'study'. Ecology in the strict sense of the term, accordingly, means 'study of the house', that is, of the home or environment of any given biotic or abiotic aspect. From this it follows logically that all elements of the environment are seen in relation to each other, for they are studied in their mutual relationships. What matters, is their interrelationship. This is exactly what the study of social relationships is about. People as members of groups and groups themselves are studied in relation to each other and in relation to other aspects of their ekos/enyironment.

If the National Parks Board values the admission of human tourists to the national parks. this in itself already implies an acknowledgement of the intertwining of the natural heritage and the cultural heritage. This implication becomes even stronger in the light of the fact that the National Parks Board has for a considerable time been accepting the conservation of the human cultural heritage as part of its task (cf. National Parks Board 1988). The acceptance by the National Parks Board of the so-called Gland declaration of the International Union for the Conservation of $\mathrm{Na}$ ture and Natural Resources (IUCN) implies the same acknowledgement, in this case expressed in a strong formulation which penetrates to the heart of conservation and in which human dependence and impact on the environment feature prominently (cf. IUCN 1980). In this way the National Parks Board has declared that the social aspect of the environment is inherently part and parcel of the ekos and that ecology therefore cannot exclude this aspect. Small wonder, then. that seminars on the social involvement of national parks and similar efforts are now being undertaken as part of the responsibilities of institutions of conservation, and that the Ex- ecutive Committee of the National Parks Board has even identitied several key strategies in an effort to address the social responsibility of the National Parks Board as a conservation body (cf. Robinson 1992). Even if the socio-political and socio-economic realities of present-day South Africa had not forced us to pay serious attention to this matter, there would still have been scientific grounds for not only realising that the inherent logic of ecology itself necessitates the acknowledgement of the interrelatedness of nature and culture, but also to take the social involvement of the National Parks Board seriously for ecological reasons.

When we speak of the human factor and the products of the human mind in this context, we speak of culture, not in the restricted sense of literature, theatre, music and other forms of art, but in the broad sense. This includes the comprehensive social reality, including its political and economic facets. We are concerned with the underlying relations between humans by virtue of which communities are formed, with the dynamics of such communities in the context of their relations to each other, and with the relations between the communities and their environment - including the issues of land, natural resources, political and economic mechanisms in which these relations are expressed. All of these aspects and processes are interdependent. If, therefore, we wish to address meaningful social relations, the central concept of concern to us is interrelationship, for, if any one of these aspects is addressed, the others are also involved. By the same token, social involvement is necessarily involved when any traditional aspect of conservation is addressed.

\section{Holism}

This perspective is a holistic conception of reality in the full sense of the lerm. If, then. the central concept of our topic is interrelatedness, we shall have to take into consideration what holism entails. The most common popular misconception in South Africa is that 'holism' is the result of the capitulation to 
British imperialism by General J. C. Smuts. Inspired by political perceptions, the notion took root that Smuts wished the Afrikaner to dissolve in a British empire devoid of identity, that 'all' was to be made one big 'whole' and that differences should therefore be eradicated. However, the opposite is true. Smuts in fact emphasised the multifariousness of reality by demonstrating the interrelationship of different aspects of reality. The one needs the other precisely because they differ. Interrelatedness does not mean the eradication of distinctions or the negation of identity, but the interdependence of those aspects of reality that are different from each other.

In ecological circles the notion of a holistic perspective, notably that everything is related to everything, is often invoked. In practice, however, this conviction is often contradicted by the tacit assumption that 'everything' only refers to what is usually called 'natural' reality. It is rather surprising when one considers that well-known holistic thinkers have been emphasising for many years that this cannot be done, and whole books have even been

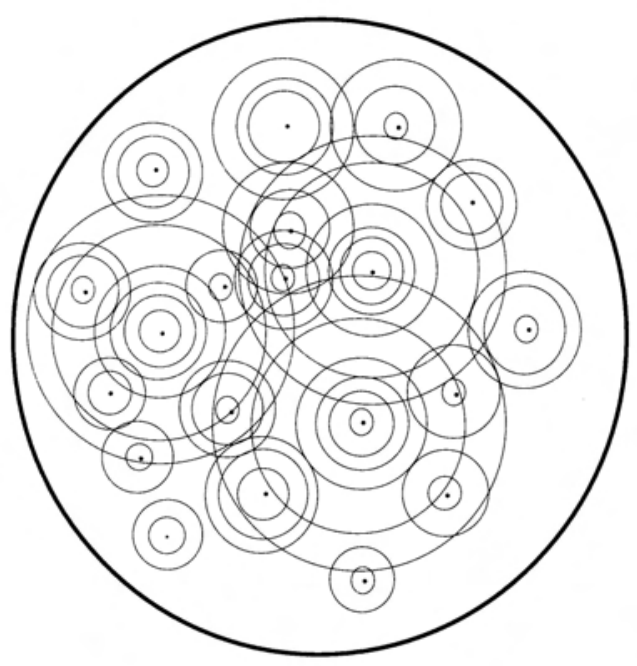

Fig. 2 .

devoted to the topic (e. g. Bergson 1919, Chardin 1966). Since there cannot be more than one 'all', 'everything' must mean everything. A true holistic look at a species, an interspecific process (such as predator-prey relationships), an ecosystem, a biome or the biosphere will therefore always be sensitive to the concentric circles within which the lot of that object is interwoven with that of other aspects (cf. Fourie et al. 1990).

Any aspect of reality, from a tuft of grass to a river, from an antelope to a human being, is involved in relationships that can be represented by expanding and overlapping concentric circles (cf. Fig. 2).

At some stage all is encompassed in one circle. All is thus related to all. The tuft of grass and the river relate to one another, the one growing as it does on the bank of the other; both relate to herbivores who utilise them; all of these relate to human communities who utilise them for irrigation, biltong, pasture and thatch (cf. Fourie 1991). This may sound over-familiar, but it means that anyone who is involved in the conservation of grass, rivers or antelope, necessarily has a social responsibility. The moment human society is regarded as an unwanted intruder, the holistic principle has been jettisoned - and then the whole conservation principle of the IUCN and National Parks Board collapses.

\section{Harmony}

The basic function of holism, or, rather, the wholeness expressed in the interdependence of so many facets, is harmony. Each facet has its own role to play or niche to fill. Interdependence works on the principle of give and take, of checks and balances. The thrust of this principle is to effect equilibrium or harmony. All aspects of reality play this role automatically or by instinct. That is, all save one - the human species. We have a choice. The only species, the only aspect of the ekos, who can choose whether or not to uphold the equilibrium, is the human species. Where this freedom of choice exists, we find responsibility. 
Humans are the only ones who can, by choice, disturb the harmony. The cliché of conservation, that we are the only ones who can conserve or destroy our planet' is true by virtue of this fact.

If this is true, then the survival of ecosystems and of the biosphere itself depends on the ability of humans to create and uphold harmony of the physical aspect of the environment with the socio-economic aspect of the environment. So we again find ourselves faced with the conclusion that, by definition, conservation includes serious attention to social relationships within the biosphere that we inhabit.

Serving the preponderance of harmony entails respect for all members of the environment, human as well as non-human. Then the social aspect requires the same. Society at large and in particular the communities directly associated with the various parks need to be approached as respected partners. Therefore it is to be welcomed that the motif of respectful partnership is incorporated in the Policy Statement approved by the National Parks Board on 9 September 1993 (cf. also Robinson 1992). It is, in fact, surprising that this element has only been given such official and public currency as recently as the last couple of years, since the principle flows so naturally from conservation itself that conservation without social involvement is intrinsically a contradiction in terms.

\section{A proposed model for social involvement}

There are various models according to which society can be described and social involvement can be planned.

For example, the conflict model associated with Karl Marx and Max Weber (cf. Weber 1947, Collins 1985), according to which the processes in society take place as a result of the struggle between privileged and oppressed. In the present South African context this model seems at first sight to address the realities. It may indeed give a picture of what in fact has been going on for years. However, it is not sufficient for the plamning of meaningful social interrelationships because it accepts conflict as the only possibility and a win-lose situation in which the winner takes all and the loser loses all. Only one perspective prevails, which is projectionism and a narrowing down of reality and therefore a negation of a holistic respect for the manysidedness and varieties in a society as well as its environment.

Another model, not as well-known as the previous one but helpful in the South African context, is the so-called symbolic model, espoused by B. Malina. His interest lies primarily with Near Eastern societies, but is applicable in many societies including our own (Malina 1982). According to this view people respond not only to the facts of the situations in which they find themselves (such as privilege or oppression), but according to the way they read and interpret the situations and what they expect from them (in terms of the battery simile used earlier: if they want a circle they see to it that the circle is sanctioned as the only visible projection of the battery and the only one tolerated). This model may cater for the high level of expectations raised in our country over recent years, but it only addresses this aspect. Like the previous model. it is only helpful as a description of what has in fact taken place and not for constructive planning of what ought to take place.

In 1982 a third model was given theoretical expression by the social historian B. O. Long. Under the influence of the French sociologist, E. Durkheim, whose work is noted for its emphasis on the interdependence of societal structures and individuals (Durkheim 1933), he concentrates on explaining historical societal processes. This approach can be called a 'structural-functional model of society'. In my opinion it is very suitable for a project as the one now embarked upon by the National Parks Board. It needs further refinement and adaptation, but it can be applied to the South African society along the lines of the argument developed in this paper. According to 
this model (cf. Long 1982), which can for convenience be represented as a pyramid (cf. Fig. 3; Mayes 1989), the basis is ecological, embracing as it does nature and natural resources, that is, the physical environment upon which all the other strata of society are built and upon which they are dependent. Next comes the socio-economic layer, comprising the societal aspects like housing, education and health services, the agricultural, industrial and financial aspects of society

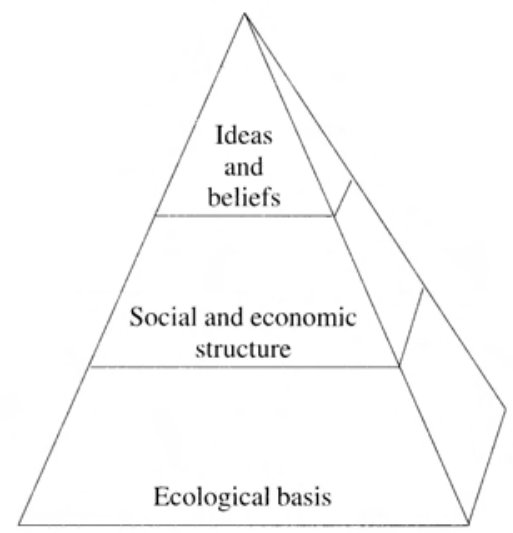

Fig. 3.

which interrelate thoroughly with the basic layer. These demands of society have everything to do with parks and their neighbours, because they bear upon the topical issues such as land claims and social benefits to be gleaned from the very existence of parks by their rural neighbours. At the pinnacle comes the last layer of society, namely the ideas, ideals and beliefs of society and their expression in artistic media. This is an important aspect, since it shapes the hearts and provides the perspectives through which the members of society perceive reality, in other words, it profoundly influences the world view which determines attitudes.

If this model is followed in the development of social relationships by our national parks, it will have, in my opinion, the greatest chance of achieving lasting success because it will be true to the holistic application of the principles of ecological harmony inherent in conservation which have formed the mainstay of National Parks Board activities over the years. It will also be true to the requirements of societies on the borders of the parks that have been expressed regularly over the last few years. Finally, it will be equal to the demands of the new democracy emerging in South Africa.

\section{Some practical considerations}

It will demand of the National Parks Board to simultaneously think on a small and a large scale - as true ecologists are supposed to be able to do (being known as they are for the insight that, say, the flightless dung beetle is not inferior to the African elephant). Ingenious plans to facilitate neighbouring communities to benefit from assets such as thatch, fuel, hides, cheap meat, a commissioned curio trade and employment will need to be made. Social services, such as housing, schooling, medical care and general medical services, will have to be developed much further than they have. Negotiation and joint decision making will have to be engendered where common interests are at stake, such as upstream agricultural interests. Highly controversial issues such as land claims and their concomitants such as grazing rights and compensation where parks have, as a result of apartheid, benefited to the detriment of societies will have to be handled 'in a context of partnership' as stated unequivocally in Paragraph 2 of the Policy Statement of the Board (National Parks Board 1993).

This means that one basic error is to be avoided at all costs: The support of the bordering communities and the community at large should not be 'bought' by social involvement in order to attain an implied more important goal. The National Parks Board should become involved in such projects because these communities are important in 
themselves. After all, that is what the holism of the ecological mind believes.

Another basic error should also be studiously avoided: Talking down to communities is worse than not embarking on the undertaking of social involvement at all. I am not referring to training and schooling, where superior expertise obviously has to be provided to those in need of it (and they usually accept it readily). I am referring to communication in negotiations which emulate the old-style paternalistic negotiations of yesteryear: 'We sit around a table and, although we will accept the posture of listening to you, we will tell you why we are right about your erroneous views on historical rights, land claims and grazing rights'. This will practise the classical fallacy of projectionism. It will be betray the presence of poor science, so that both ecology and conservation would be better off without it. For it will, on the practical level. demonstrate a blinker vision of the interests of conservation, and, on the scientific level. a lack of understanding that conservation is all about the interrelationship of the whole of the environment.

\section{References}

Baron, R. A. ANd D. BYrne, 1987. Social Psychology understanding human interaction. Boston: Allyn \& Bacon.

Bergson, H. 1919. L'énergiespirituelle. Paris: Alcan.

Chardin, P. Tellatid de. 1966. Man's place in nature: the human zoological group. London: Collins.

Colu. York: Oxford University Press.

Cомте, A. 1830-42. Cours de philosophie positive. Vols 1-6. Paris: Bachelier \& Fregres.

Durkheim. E. 1933. The division of labor in society. New York: Free Press. (Trans. by G. Simpson.)
Fot RIE, J. 1991. The concepe of life: on the social mote of conservation areas. Koeduc $34(2): 157-165$.

For kIE, J.. S.C.J. Ja kERI ANU J.A. LUNDER. 1990. Environmental education - an approach based on the concept of life. Koedoe 33(1):95-109

HEGEL. G.W.F. I1807] 1969-71, Phämomienologicdes Geistes. Frankfurt a. M.: Suhrkamp-Verlag.

HogG, A. AND D. ABrams. 1988. Social identificanons: a social psychology of intergreup relations and group processes. London: Routledge.

HuME, D. | 1739-40| 1956. A treatise of human nature. London: Dent.

INTERNATIONAL UNION FOR TIIE CONSTRVATION OF NA. TIRE AND NATIIRAL ResotirCES. 1980). World comtservation strategy. Gland: IUCN.

LoNG, B. O. 1982. The social world of ancient Israel. Interpretation 36: 243-255.

Malina, B. 1982. The social sciences and biblical interpretation. Interpretation 37:229-242.

MARX. K. [1859] 1956. Zur Kritik der politischent Ökonomie. Berlin: Dietz-Verlag.

Marx, K. [1867] 1956. Das Kapital. Berlin: Diel/Verlag.

MarX, K. AND F, ENgels, [1845-46] 1956. Die deutsche Ideologie'. Berlin: Dietz-Verlag.

MArEs, A.D.H. 1989. The Old Testament in sociological perspective. London: Marshall Pickering.

MCLelian, D, 1978. The thought of Karl Marx. London: Macmillan.

Natonal Parks Board. 1988. National Parks in South Africa. Policy statement of the National Parks Board of Trustees. Pretoria: NPB.

Robinson. G.A. 1992. The National Parks Board. National Parks Board: Internal publication.

Roвınsox, G.A. I993. Ekotoerisme: die gemeenskap moet ook voordeel trek. Custos Octoher 1993 : 6-11.

Rouche, J.S. ANo L. WARREs. 1966. Sociology. An introduction. Totowa, N.J.: Littlefield \& Adams.

SinClaIR, W.A. 1960. The traditional formal logic. London: Methuen.

SmuTs, J. C. [1926] 1987. Holism and evolution. Cape Town: N \& S Press.

URmson, J.O. (ed.). 1983. Western philosophy and philosophers. London: Hutchinson.

WeBer, M. 1947. Theory of social and ecomomic organization. New York: Free Press. (Trans, by A. M. Henderson \& T. Parsons.) 